\title{
Forensic Anthropology: A Paradigm Shift in Classical Discipline
}

\section{Anup Kumar Kapoor*}

Department of Anthropology, University of Delhi, Delhi-110007, India

*Corresponding author: Anup Kumar Kapoor, Professor, Department of Anthropology, University of Delhi, Delhi-110007, India, Tel: 011-27667329; Fax: 011-27666614; E-mail: anupkapoor46@rediffmail.com

Received Date: June 22, 2016; Accepted Date: June 24, 2016; Published Date: June 28, 2016

Copyright: ( 2016 Kapoor AK. This is an open-access article distributed under the terms of the Creative Commons Attribution License, which permits unrestricted use, distribution, and reproduction in any medium, provided the original author and source are credited.

Citation: Kapoor AK (2016) Forensic Anthropology: A Paradigm Shift in Classical Discipline. J Forensic Anthropol 1: 106. doi:10.4172/jfa.1000106

\section{Opinion}

Forensic Anthropology deals with the anthropological methods and techniques to resolve the issues related to medico legal significance. It usually focuses on the identification of human remains, especially pertaining to the evidences of foul play. Seeds of antecedents of forensic anthropology were sown in the field of skeletal analysis, where anatomists and physicians applied their knowledge of skeletal anatomy and variations. The traditional role played by forensic anthropologists comprised of age, sex, race and stature estimation of skeletal remains that assist in personal identification. During this age, a variety of methods were used in skeletal analysis including visual observation, metric analysis, radiography and histology.

In recent years, the niche of Forensic Anthropology has become more diversified due to a variety of problems faced by practitioners beyond classical skeletal analysis. Modern Forensic Anthropology has roots in living personal identification with reference both to the new diagnostic physical traits of the human body and to the identification of humans from images captured by surveillance systems. The relatively new role of the forensic anthropologist in the domain of living identification has grown manifold in the last decade. The diagnostic physical traits or characteristics of human body that assist in identification include DNA, fingerprints, face, iris pattern, retina pattern, palm prints, hand geometry, foot prints, lip prints, ear pattern, hand vein and nail patterns. The advances in image enhancement and image processing are enabling the practitioners of forensic anthropology to microscopically analyze the evidences such as fingerprints, bite marks and footprints.

The past decade has seen a considerable proliferation of researches in the field of sex, age and ethnicity prediction from lip prints, iris texture, fingerprints, DNA and handwriting. Determination of age, sex and ethnicity is crucially important in crime settings to narrow down the possible matches for suspects and to confirm the identity. The classical methods of forensic anthropology refer to the conventional anthropometry and indices to verify the biological profile of an individual. In the current era, unique physical traits or patterns of human body and DNA profiling has revolutionized the field of identification with great accuracy.

In Indian scenario, there are ample opportunities for researches on ethnicity identification as more than five thousand ethnic groups exist in India. Much of the recent growth of forensic anthropology in India has taken place in sex and ethnicity identification through handwriting, fingerprint, facial features and lip prints, making forensic anthropology a stronger and diverse discipline. The division of forensic anthropology in India has flourished tremendously since the advent of biometrics and sound scientific computer application

Simultaneously, forensic anthropologists are also contributing in the virtual creation of model of size, shape and proportions of individuals present at the crime scene through morphometric analysis. For the reconstruction of crime events, cranio-facial approximation, forensic taphonomy and estimates of post-mortem interval function as key components of forensic anthropology.

Today, the science of forensic anthropology has also created data banks to gather information from documented forensic cases and researches to automate the process of identity through a series of statistical and computer programs. These revolutionary developments have made significant contributions in the medico legal contexts.

The modern expertise of forensic anthropology is highly requested in the field of mass disaster and forensics. The discipline has developed the most over last few years concerning the human remains analysis, trauma analysis, cranio-facial reconstruction and personal identification. The novel applications of forensic anthropology are continuously generating fascinating and sound researches in the medico-legal settings. In the upcoming years, major contributions will come from the researches on automated living identification which will be based on the traditional approaches of forensic anthropology. 